\title{
Microdialytical monitoring of uric and ascorbic acids in the brains of patients after severe brain injury and during neurovascular surgery
}

\author{
H Langemann, T Feuerstein, A Mendelowitsch, O Gratzl
}

\begin{abstract}
Objectives-Microdialysis has been extensively used to monitor brain metabolism in the extracellular fluid of patients with severe head injury, to detect the onset of secondary ischaemic damage. The aim was to investigate whether concentrations of uric and ascorbic acids were altered in such patients. Both these compounds play a part in free radical metabolism, which is accelerated after ischaemia and brain injury.
\end{abstract}

Methods-Patients with aneurysm or bypass operations were monitored intraoperatively to assess concentrations in minimally disturbed tissue. Afterwards, 13 patients with severe head trauma were monitored for up to 13 days in the intensive care unit.

Results-Intraoperatively, concentrations of both ascorbic and uric acids were significantly higher in the bypass group than in patients with aneurysm, which might be attributed to chronic ischaemic conditions caused by the unilateral occlusion of the carotid artery. In the patients with trauma, mean values of uric acid, varying between $6 \mu \mathrm{M}$ and $180 \mu \mathrm{M}$, did not correlate with type of injury (contusion or diffuse) or duration of monitoring time. Patients who died had significantly higher concentrations of uric acid than those with a good outcome. Ascorbic acid could be detected only intermittently, probably due to technical problems. Concentrations of these two compounds could not be correlated with clinical findings during the course of monitoring.

Conclusions-Although uric and ascorbic acids are influenced by ischaemic conditions-for example, in bypass patients, neither compound is suitable for monitoring for free radical activity after severe head injury. Patients with a bad outcome tended to have higher concentrations of uric acid.

(F Neurol Neurosurg Psychiatry 2001;71:169-174)

Keywords: ascorbic acid; brain; microdialysis; trauma; uric acid

Delayed secondary damage is known to worsen the outcome in many patients with traumatic brain injury. During the past decade neurochemical monitoring of the brain with microdialysis has been widely used in these patients. The aim has been to detect changes in brain metabolism that indicate the onset of this secondary damage at a time when it might still be treated. ${ }^{12}$ Secondary damage is thought to be ischaemic in origin; indeed, there is evidence of ischaemia in almost $90 \%$ of brains which come to postmortem after injury, even in the absence of increased intracranial pressure (ICP) or hypotension. ${ }^{3}$ The microdialytical variables that have been chosen by investigators in this field therefore reflect various changes that occur in the extracellular fluid (ECF) during ischaemia. For instance, glucose, lactate, and pyruvate ${ }^{145}$ are involved in energy metabolism, and glutamate is an excitatory amino acid that is released into the ECF in large quantities during ischaemia and after trauma. ${ }^{6}$

However, a neurochemical event that has not received much attention in this respect is free radical generation, ${ }^{7-9}$ although this process is known to play an important part in ischaemia and reperfusion damage, leading, for example, to lipid peroxidation and membrane breakdown. We were therefore interested in using microdialysis to monitor two substances, ascorbic acid (Asc) and uric acid (UA), which are known to be involved in free radical processes. Ascorbic acid is a water soluble free radical scavenger and UA, besides having antioxidative properties, is a putative marker of free radical activity via the xanthine oxidase pathway. Our aim was to discover whether there were changes in concentrations of these two substances in patients with brain damage which could be correlated with clinical findings. The first steps were to detect them in dialysates collected during cerebrovascular operations, to determine the feasibility of measurement, and to get an idea of concentrations in minimally disturbed tissue. Afterwards they were monitored in a series of patients with traumatic brain injury.

A preliminary report has been presented in poster form. ${ }^{10}$

\section{Methods}

The procedures were approved by the ethics committee of the Cantonal Hospital, Basel. Patients were treated according to the standard protocol of our clinic.

All microdialysis apparatus was obtained from CMA/Microdialysis, Stockholm, Sweden.

INTRAOPERATIVE PROCEDURES

Measurements were carried out during 11 aneurysm operations and six extra-intracranial bypass operations. Temporary clipping and burst suppression with barbiturates were performed in all patients. The bypass patients 
Table 1 Clinical data and mean uric acid values in dialysates from 13 patients with severe head injury monitored in the intensive care unit

\begin{tabular}{llllllll}
\hline Patient No & Age, sex & $\begin{array}{l}\text { Hours } \\
\text { monitored }\end{array}$ & $\begin{array}{l}\text { UA mean }(S D) \\
\mu M\end{array}$ & $\begin{array}{l}\text { Time after injury of } \\
\text { probe insertion }\end{array}$ & CT finding & GOS & $\begin{array}{l}\text { ICP/CPP } \\
\text { mean }\end{array}$ \\
\hline 59 & $60, \mathrm{M}$ & 148 & $20.2(7.4)$ & $16 \mathrm{~h}$ & $\mathrm{c}$ & 2 & $<15 />60$ \\
60 & $68, \mathrm{M}$ & 57 & $89.4(20.8)$ & 3 days & $\mathrm{c}$ & 2 & $<15 />60$ \\
61 & $21, \mathrm{~F}$ & 232 & $21.8(8.0)$ & $12 \mathrm{~h}$ & $\mathrm{~d}$ & 5 & $<15 />60$ \\
64 & $44, \mathrm{M}$ & 118 & $10.2(1.5)$ & $12 \mathrm{~h}$ & $\mathrm{c}$ & 3 & $<15 />60$ \\
65 & $57, \mathrm{M}$ & 80 & $135.9(81.2)$ & $6 \mathrm{~h}$ & $\mathrm{~d}$ & 1 & $48 / 50$ \\
66 & $31, \mathrm{M}$ & 150 & $10.4(10.0)$ & $5 \mathrm{~h}$ & $\mathrm{c}$ & 4 & $<15 />60$ \\
67 & $26, \mathrm{M}$ & 38 & $30.0(12.4)$ & $7 \mathrm{~h}$ & $\mathrm{c}$ & 2 & $26 / 61$ \\
68 & $54, \mathrm{M}$ & 66 & $101.2(37)$ & $8 \mathrm{~h}$ & $\mathrm{c}$ & 1 & $<15 />60$ \\
69 & $24, \mathrm{M}$ & 312 & $26.6(12.1)$ & $4 \mathrm{~h}$ & $\mathrm{c}$ & 2 & $<15 />60$ \\
70 & $37, \mathrm{~F}$ & 20 & $19.8(33)$ & $7 \mathrm{~h}$ & $\mathrm{~d}$ & 5 & $<15 />60$ \\
71 & $47, \mathrm{M}$ & 48 & $6.0(2.3)$ & $8 \mathrm{~h}$ & $\mathrm{~d}$ & 2 & $<15 />60$ \\
72 & $42, \mathrm{~F}$ & 68 & $33.5(14.4)$ & $?$ & $\mathrm{~d}$ & 1 & $<15 />60$ \\
73 & $37, \mathrm{M}$ & 59 & $183.9(30)$ & $17 \mathrm{~h}$ & $\mathrm{~d}$ & 1 & $<15 />60$ \\
\hline
\end{tabular}

CT finding: $\mathrm{c}=$ contusion; $\mathrm{d}=$ diffuse injury.

GOS=Glasgow outcome scale. $1=$ dead; $2-3=$ poor; $4-5=$ good.

received heparin locally at the site of the bypass. The method used has been described previously. ${ }^{11}$ Immediately after the craniotomy a $1 \mathrm{~cm}$ cut was made in the dura and the probe (4 $\mathrm{mm}$ membrane, $0.5 \mathrm{~mm}$ diameter), which had been previously sterilised at $60^{\circ} \mathrm{C}$ with ethylene dioxide, was inserted into the cortex (frontally for the aneurysm operations; temporally for the bypass operations, $1-1.5 \mathrm{~cm}$ from the bypass site). Probes were perfused with $0.9 \%$ saline at a flow rate of $2 \mu 1 / \mathrm{min}$. In two patients with very short operation times a flow rate of $4 \mu \mathrm{l} / \mathrm{min}$ was used. Samples were collected every 20 or 30 minutes until the dura was closed (total monitoring time 100-375 minutes for aneurysm operations, 110-225 minutes for bypass operations).

\section{INTENSIVE CARE}

Thirteen patients with severe head trauma, who were all comatose with a Glasgow coma score $(\mathrm{GCS})<8$ before and during monitoring, were monitored in the intensive care unit (ICU). The probe was inserted into normal tissue, as defined by CT; this was usually frontally on the right side, using a four lumen transcranial screw. ${ }^{12}$ CMA 70 microdialysis probes (sterile, $1 \mathrm{~cm}$ membrane) were perfused with sterile perfusion fluid (artificial CSF from CMA/Microdialysis) at a flow rate of 0.3 $\mu 1 / \mathrm{min}$. Samples were collected hourly.

The clinical and microdialytical data of the patients are given in table 1 .

ANALYSIS

Samples collected during operations were immediately cooled and kept at $-20^{\circ} \mathrm{C}$ or cooler until analyzed. Samples collected in the intensive care unit were analyzed in a CMA/ 600 analyzer (a self calibrating autoanalyzer using enzyme fluorimetric assays) for glucose, lactate, and glutamate $(2.5 \mu \mathrm{l})$ before cooling. Samples were later analyzed ( 5 or $10 \mu \mathrm{l}$ ) for UA and Asc using reverse phase high performance liquid chromatography (HPLC) with electrochemical detection at a gold electrode set at $0.65 \mathrm{mV}^{13}$ Glucose and lactate were also analysed using enzymatic methods. ${ }^{11}$

Basal concentrations during operations were calculated as the mean of all samples excluding the first ones, and those collected during surgical retraction. Statistical analysis was carried out using the program StatView 5.0 (SAS Institute, North Carolina, USA).

\section{RECOVERY}

The microdialysis probes used had a cut off of $20000 \mathrm{Da}$. The molecular weights of Asc and UA are 176 and 168 respectively. In vitro recoveries at $2 \mu \mathrm{l} / \mathrm{min}$ with a membrane length of $4 \mathrm{~mm}$ were about $12 \%$ for Asc and $21 \%$ for UA. Using a $10 \mathrm{~mm}$ membrane with a flow rate of $0.3 \mu \mathrm{l} / \mathrm{min}$, in vitro recovery for UA was about $85 \%$, for Asc $60 \%$.

\section{Results}

INTRAOPERATIVE

Uric acid and Asc could be detected in dialysates from all patients during the cerebrovascular procedures. Basal concentrations in the patients with aneurysm (minimally disturbed tissue) were mean (SEM) 5.6 (0.6) $\mu \mathrm{M}$ for UA, and $7.7(0.8) \mu \mathrm{M}$ for Asc. Concentrations of both UA and Asc were significantly higher (Mann Whitney $U$ test) in patients undergoing bypass operations (8.5 (0.9) $\mu \mathrm{M}$ for UA, 10.3 (0.7) $\mu \mathrm{M}$ for Asc (fig 1).

Temporary clipping with local application of heparin had no effect on any microdialytically measured variable. In six of the patients retraction led to changes typical for ischaemic conditions in the region of the probe (increases in

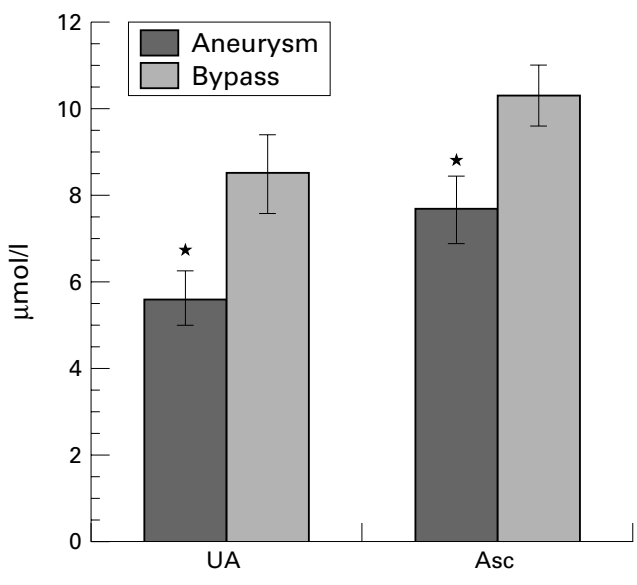

Figure 1 Mean (SEM) concentrations of uric acid (UA) and ascorbic acid (Asc) in cortical dialysates collected from patients undergoing cerebrovascular operations. Aneurysms, $n=11$; bypass operations, $n=6 ;{ }^{\star} p<0.05$, Mann Whitney $U$ test. 

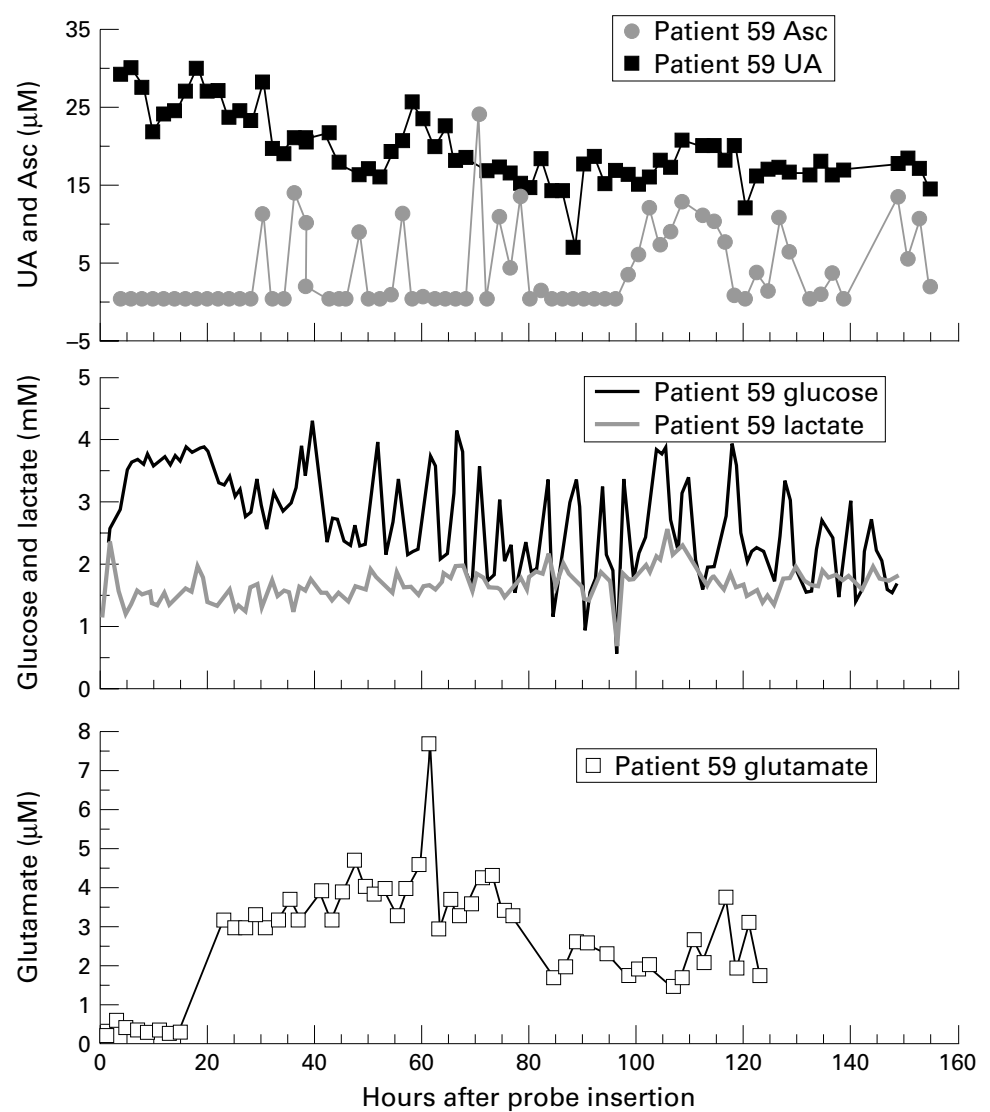

Figure 2 Time course of microdialytical monitoring of uric acid (UA), ascorbic acid (Asc), glucose, lactate, and glutamate in patient 59.
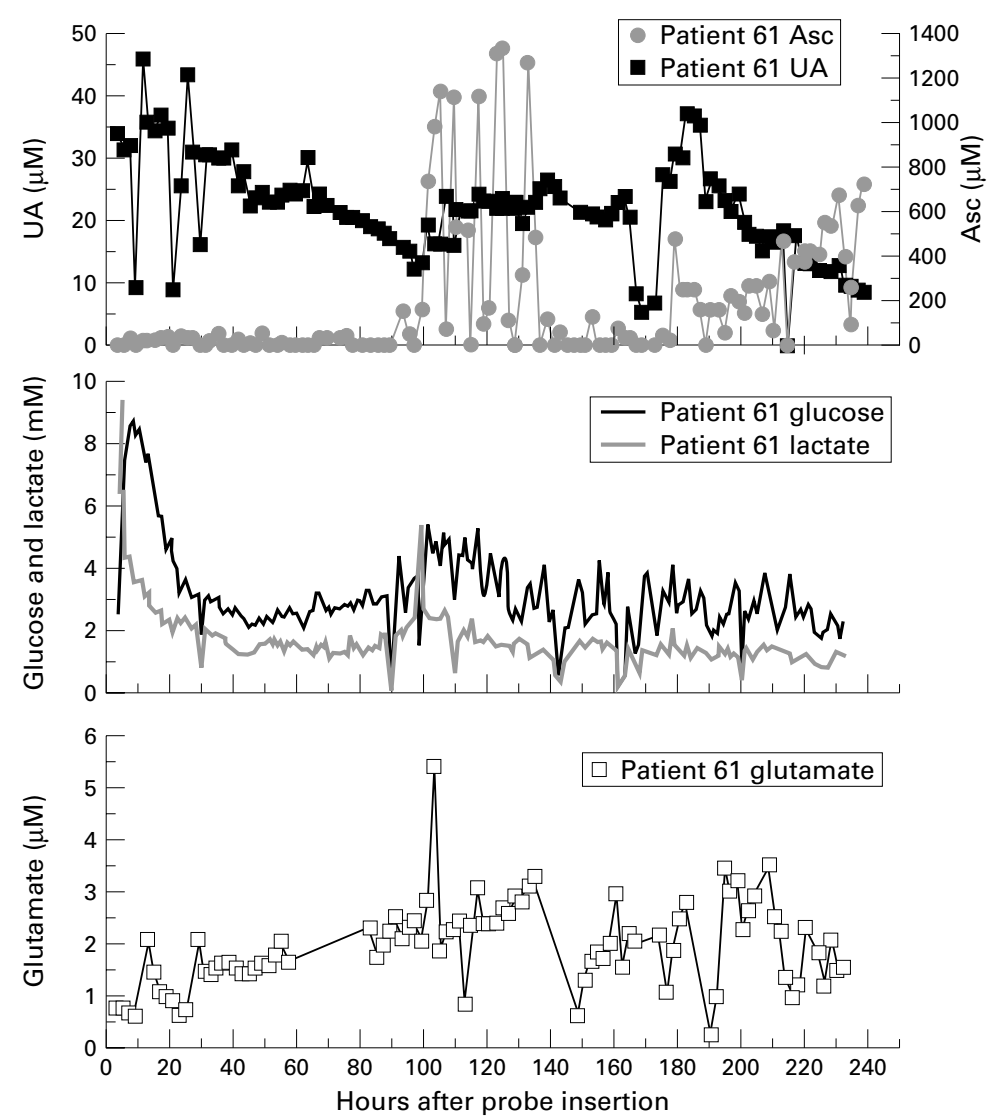

Figure 3 Time course of microdialytical monitoring of uric acid (UA), ascorbic acid (Asc), glucose, lactate, and glutamate in patient 61.
Asc, UA, and lactate and reductions in glucose and $\mathrm{pH}$ ). Conditions normalised rapidly, sometimes even before the end of retraction. ${ }^{11}$

CASE REPORTS

Three of the 13 patients are described in detail. Results for UA, Asc, glucose, lactate, and glutamate for the three patients are shown in figures 2, 3, and 4 and ICP together with cerebral perfusion pressure (CPP) for patient 65 in figure 4).

\section{Patient 59}

Patient 59 (male 60 years old, fig 2) fell down the stairs. At the scene of the accident the patient was unconscious with normal flexion of the limbs (GCS 6). Brain CT showed a left occipital fracture of the skull, an intracerebellar haemorrhage, a subarachnoid haemorrhage, and blood within the cisterna magna. The haemorrhage compressed the brain stem, so an occipital craniectomy was carried out and the haematoma was evacuated. Then the patient was transferred to the intensive care unit, where a multiparametric screw was inserted into undamaged tissue on the right side. During the period of monitoring the ICP never went above 13 and CPP was never pathological. All other clinical variables remained stable and within the normal range. Monitoring time was 7 days. Glucose, lactate, and glutamate all showed acceptable values. Ascorbic acid was measurable in less than half the samples, remaining under $25 \mu \mathrm{M}$. Uric acid was not high and showed a relatively stable course, the initial value of about $30 \mu \mathrm{M}$ being reduced to about $18 \mu \mathrm{M}$ at the end of monitoring. The outcome after 6 months was severely handicapped (Glasgow outcome scale (GOS) 3).

\section{Patient 61}

Patient 61 (female, 21 years old, fig 3) had a traffic accident, resulting in multiple fractures (craniofacial and of the lower limbs). Brain CT did not show any intracranial pathology. Initially the patient was unconscious with normal flexion of the limbs (GCS 6). The probe was inserted into undamaged tissue frontally on the right side. At the start of monitoring, ICP was normal. However during the first 36 hours there were several short periods with high ICP, during which ICP rose to over 100 $\mathrm{mm} \mathrm{Hg}$ for 10-15 minutes. Afterwards, ICP was stable and in the normal range. The patient was in a coma for 12 days before she regained consciousness spontaneously. In this patient glucose, lactate, and glutamate were normal. At first Asc was not measurable, then there was a sudden unexplained episode of extremely high concentrations (over $1000 \mu \mathrm{M}$ ) from 100 to 140 hours, followed by several hours when it was again not measurable. During this time, UA was relatively stable at about $25 \mu \mathrm{M}$. At 190 hours, UA started to decrease to a final concentration of $10 \mu \mathrm{M}$ and Asc started to increase. Shortly afterwards the patient became conscious. She recovered without any neurological deficits (GOS 5). 

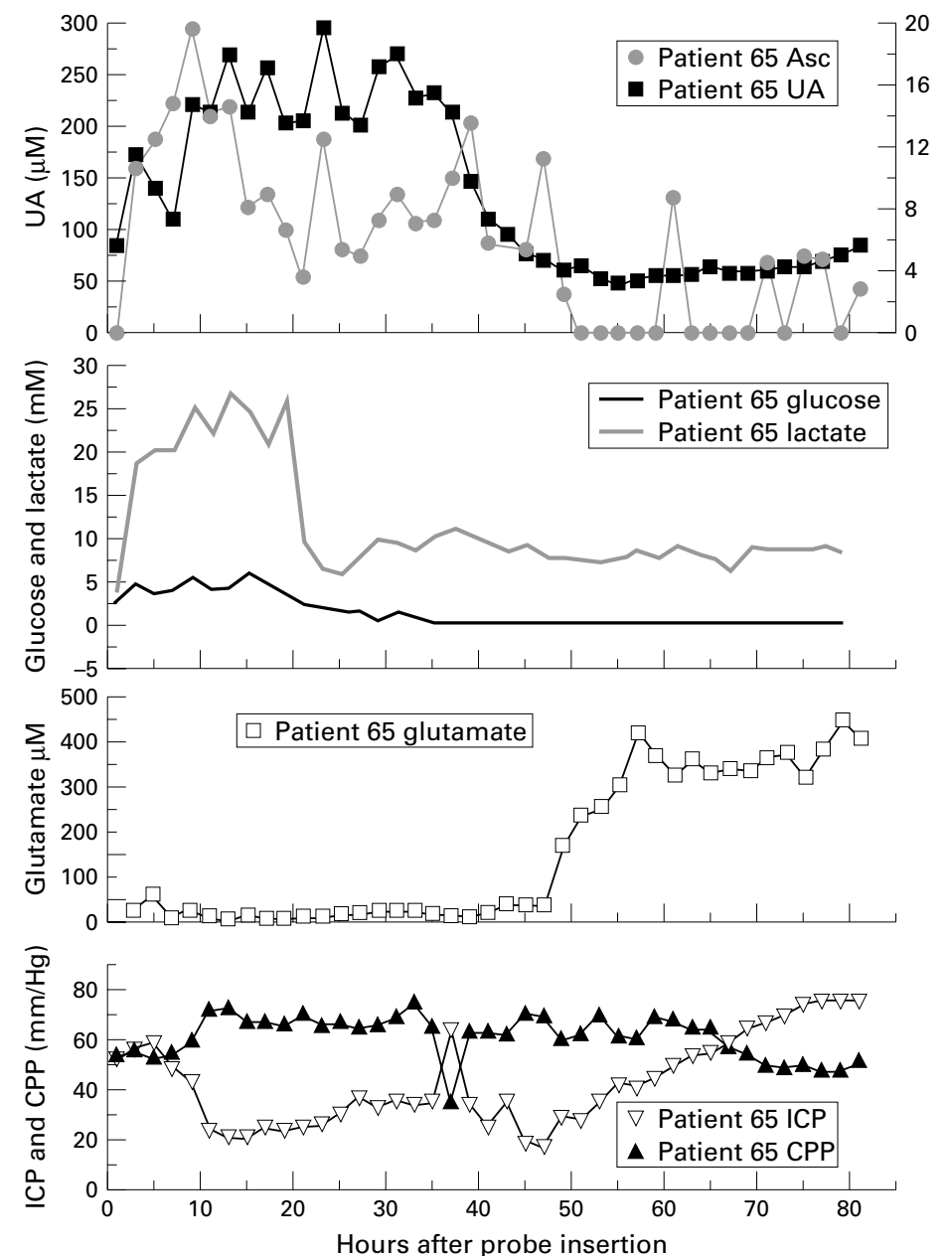

Figure 4 Time course of microdialytical monitoring of uric acid (UA), ascorbic acid (Asc), glucose, lactate, and glutamate, together with values of intracranial pressure (ICP) and cerebral perfusion pressure (CPP), in patient 65.

Patient 65

Patient 65 (male, 57 years old, fig 4) had a history of alcoholism. He was found unconscious in the street, with normal flexion of the limbs (GCS 6). Brain CT showed an acute subdural haematoma temporo-occipital on the right side, which was evacuated. A multiparametric screw was inserted just after the operation (which was about 5 hours after the accident) frontally on the left side, because of the craniectomy on the right side. The initial ICP was high $(55 \mathrm{~mm} \mathrm{Hg})$ but therapy with hyperventilation and mannitol lowered the ICP down to $20 \mathrm{~mm} \mathrm{Hg}$. Twenty four hours later the ICP started to rise again (up to $95 \mathrm{~mm} \mathrm{Hg}$ ) and all attempts to lower it failed. The GCS fell to 3. The patient was pronounced brain dead the next day. This patient showed the classic picture of ischaemia: glucose diminishing to zero, high lactate, and an enormous rise in glutamate combined with high ICP and low CPP at 48 hours after probe insertion (fig 4). Initially UA was very high (over $200 \mu \mathrm{M}$ ), indicating massive damage; these concentrations started to diminish rapidly at about 35 hours. Ascorbic acid, which also showed high values, started to diminish slightly before glutamate started to rise.
INTENSIVE CARE

Uric acid could be measured in all patients with trauma. Concentrations mostly did not show very marked changes during the course of monitoring (for example, patient 59, fig 2 ). Mean values during the monitoring period are given for each patient in table 1. Concentrations varied considerably between the patients.

Ascorbic acid could not be measured in all patients, and in those in whom it was measurable it sometimes varied greatly from sample to sample (see for instance, patients 59 and 61, figs 2 and 3 ).

Patients who died (GOS 1, n=4), had a mean (SEM) concentration of UA of 113.6 (31) $\mu \mathrm{M}$, those with a good outcome (GOS 4 or $5, \mathrm{n}=3$ ) 17.3 (3.5) $\mu \mathrm{M}$. This difference was significant $(\mathrm{p}<0.05$, Mann-Whitney $U$ test). Patients with a poor outcome (GOS 2 or $3, n=6$ ) had a mean (SEM) UA concentration of $37.5(17.8) \mu \mathrm{M}$.

\section{Discussion}

It is known that there is oxidative stress, resulting in free radical activity, during ischaemia and reperfusion, ${ }^{14}$ and after brain trauma. ${ }^{15} 16$ Free radical scavengers have been shown to be neuroprotective in experimental models of brain injury ${ }^{17}$ and ischaemia. ${ }^{18}$ Tirilazad, an aminosteroid antioxidant, has been shown to be efficacious in patients with subarachnoid haemorrhage, ${ }^{19}$ although it has not been generally recognised as a clinical neuroprotective agent. It would therefore be advantageous to be able to monitor for oxidative stress in patients in critical care. Parabanic acid ${ }^{8}$ and glycerol ${ }^{9}$ have already been suggested for this purpose. Our aim was to find out if there were changes in concentrations of UA and Asc in patients with severe head injury, which might indicate oxidative stress. There is evidence to support this idea.

Uric acid, which is the end product of purine nucleotide degradation, is an important antioxidant in the body. However, it is also itself one source of reactive oxygen species; during ischaemia and reperfusion, UA arises from xanthine in the presence of xanthine oxidase, together with superoxide radicals. Thus it has been suggested as a marker for free radical activity. Greatly increased UA has been found in cortex tissue both postischaemically and after experimental traumatic brain injury. ${ }^{20} 21$ Additionally, increased extracellular concentrations were found in rats after middle cerebral artery occlusion; this increase was only moderate at 4 hours but 13-fold after 24 hours. ${ }^{18}$ However, this increased UA does not come exclusively from free radical activity; it can also arise from the breakdown of purines in the DNA and RNA of necrotic or apoptotic cells and from breakdown of ATP and adenosine. ${ }^{22}$

Ascorbic acid is also an important antioxidant present in large quantities in the brain. It is a broad spectrum radical scavenger effective against reactive oxygen species. Although Asc, as a water soluble antioxidant, is not able itself to scavenge in the lipid compartment, it can play an important part in maintaining concentrations of the fat soluble vitamin $\mathrm{E}$, a known 
neuroprotective agent for cell membranes. There is also evidence that Asc is involved in excitatory amino acid release and that changes in its extracellular concentrations can be used as an index of such release. It is reduced in the cortex after middle cerebral artery occlusion, ${ }^{20}$ and increased in the ECF during ischaemia in both rats ${ }^{13}$ and humans. ${ }^{23}$ It has been suggested as a biochemical index of early ischaemia. ${ }^{24}$ Concentrations of Asc also increase in the ECF after experimental brain trauma. ${ }^{25}$

INTRAOPERATIVE

In the first step we were able to measure both UA and Asc in all patients during cerebrovascular operations. The values obtained during the aneurysm operations $(5.6 \mu \mathrm{M}$ for UA, and $7.7 \mu \mathrm{M}$ for Asc) represent values for minimally disturbed tissue. However in the bypass patients, cerebral metabolism has probably been affected, as this operation is carried out to relieve chronic problems of ischaemia caused by unilaterally occluded carotid arteries. Acute ischaemia is known to cause increases in extracellular concentrations of both variables. ${ }^{13}$ Thus we found higher concentrations in the bypass patients for both UA and Asc (fig 1). Ascorbic acid was also increased during ischaemic conditions caused by retraction. ${ }^{11}$

INTENSIVE CARE

We were able to detect UA in all the patients with trauma. Mean values varied between $6 \mu \mathrm{M}$ and $180 \mu \mathrm{M}$ (table 1). The very high concentrations in some patients cannot be explained by the type of injury (CT showing contusion or diffuse injury), as there was no statistical difference between the two groups (Mann-Whitney $U$ test). There was also no correlation with the duration of monitoring (Spearman rank correlation). O'Neill and Lowry ${ }^{22}$ reported a sevenfold increase in basal concentration (measured by microdialysis and voltammetry) a few days after probe insertion, in parallel with gliosis around the probe. We did not have any indication of this in our patients, values quite often becoming reduced over time. The very high concentrations in some patients might indicate damage to the blood-brain barrier, or the presence of blood in the brain in the area of probe insertion, as plasma concentrations (around $300 \mu \mathrm{M}$ ) are much higher than CSF concentrations in humans. In one patient where a routine postoperative CT showed a tiny haemorrhage around the probe, we found greatly increased UA values at the end of the operation. ${ }^{23}$ There is a tendency for the higher UA values to be associated with a poor outcome. In severely injured patients with a poor outcome there would be increased release of purine metabolites from the nuclei of damaged cells (necrosis or apoptosis). In an experiment using middle cerebral artery occlusion in the rat, we found a significant correlation between lesion size and total UA in microdialysates collected for 3 days after occlusion. ${ }^{18}$

Although we could always measure Asc during operations, it was not possible to detect this variable in every sample during monitoring in the ICU. Indeed, in some patients it could not be detected at all. This might be explained by the fact that in severe head injury and ischaemia there is ongoing peroxidation and all the Asc might be used up. But this cannot be the whole explanation. There are certainly technical difficulties, as Asc is very easily oxidised and dialysates in the ICU are collected for 1 hour without cooling. We also have evidence that Asc is degraded by high concentrations of UA (over $60 \mu \mathrm{M}$ ) in the dialysates (unpublished data). Other authors have also reported some difficulties concerning microdialysis and Asc. Thus in rats, Miele and Fillenz ${ }^{26}$ found a true basal concentration of $416 \mu \mathrm{M}$ (measured by a modification of the zero net flux method), although cortical dialysates in these animals contain maximally about $30 \mu \mathrm{M}$. Miele and Fillenz suggest that Asc is continuously oxidised in the efflux from the probe, as the tubing is known to be permeable to gases. ${ }^{27}$

We used $0.9 \%$ saline as perfusion fluid for our intraoperative measurements. On the other hand, for our critical care patients we used the CMA/600 enzymatic analyser, for which artificial CSF (containing calcium) from CMA/ Microdialysis is mandatory. Thus there is a discrepancy in perfusion fluids between our intraoperative and critical care patients, which might affect recovery. However, a recent methodological paper ${ }^{28}$ found only minimal differences in concentrations of glucose, lactate, glutamate, and pyruvate during perfusion with Ringer's solution (containing calcium) or normal saline. This comparison was performed during 24 hours in patients with head injury, using two probes inserted through the same transcranial screw and perfused in parallel with the two fluids.

There are some points of interest in the time courses of the three patients. In patient 59 (fig 2) the clinical course and microdialytic monitoring were uneventful; UA was not excessively high, and glucose, lactate, and glutamate concentrations were normal. Concentrations of UA lessened slowly during the course of monitoring, which might indicate that cell death due to the original trauma was diminishing. However the outcome was poor, the patient remaining severely handicapped. This discrepancy can be explained by the limitations of the monitoring technique. The probe, which can only monitor a limited volume of tissue, was inserted in the cortex, so that it was too far away from the infratentorial injury to detect any relevant changes. By contrast, patient 61 (fig 3) had a satisfactory outcome. In this patient UA decreased markedly, approaching the values found intraoperatively in minimally disturbed tissue, and Asc increased at the end of the monitoring period. This might indicate normalisation of the metabolism as the patient then regained consciousness. The third patient (fig 4) showed the classic picture of ischaemia 48 hours after probe insertion: very high ICP and low CPP combined with glucose diminishing to zero, high lactate, and an enormous rise in glutamate. Initially, UA was very high, indicating massive damage. As in patient 61 , UA diminished rapidly (beginning at about 35 
hours). However, in this case the reduction did not indicate normalisation of metabolism as the patient died the next day. It must be attributed to some other mechanism-for example, lack of perfusion or metabolic breakdown. Another possibility might be that UA and Asc (both antioxidants) disappear because of production of free radicals formed by the marked release of glutamate. It has been shown in rats that high extracellular glutamate leads to massive production of free radicals. ${ }^{29}$

Thus, although our intraoperative results indicate that Asc is affected by ischaemia (increased Asc during retraction, increase in bypass patients) this variable requires further evaluation in patients. It does not seem to be a suitable index for monitoring for conditions of peroxidation in patients in ICUs. This is because it is too unstable and presents problems of collection and analysis, and possibly because the probe is often inserted several hours after the original injury (table 1). Uric acid is stable and easily analyzed. However, alterations in its concentration in the ECF probably reflect long term effects (chronic ischaemia in the bypass patients, neurodegeneration) rather than acute changes in free radical metabolism leading to secondary damage. This fact makes correlation with clinical indices very difficult. However, it is of interest that high concentrations seem to indicate a disturbed metabolic state and are a sign of poor outcome in patients with trauma.

We thank Mrs F Wolf for excellent technical assistance. This study was supported by the Swiss National Research Foundastudy was supported by the Swiss National Research Founda-
tion Grant No 32-45999.95 and by the Department of Surgery, Kantonsspital, Basel.

1 Persson L, Hillered L. Chemical monitoring of neurosurgical intensive care patients using intracerebral microdialysis. cal intensive care patients using
$\mathcal{F}$ Neurosurg 1992;76:72-80.

2 Landolt H, Langemann H. Cerebral microdialysis as a diagnostic tool in acute brain injury. Eur $f$ Anaesthesio 1996:13:269-78.

3 Graham DI, Lawrence AE, Adams JH, et al. Brain damage in fatal non-missile head injury without high intracranial pressure. F Clin Pathol 1988;41:34-7.

4 Langemann H, Mendelowitsch A, Landolt H, et al. Experimental and clinical monitoring of glucose by microdialysis Clin Neurol Neurosurg 1995;97:149-55.

5 Goodman JC, Valadka AB, Gopinath SP, et al. Extracellular lactate and glucose alterations in the brain after head injury measured by microdialysis. Crit Care Med 1999;27:196573.

6 Bullock R, Zauner A, Myseros JS, et al. Evidence for prolonged release of excitatory amino acids in severe human head trauma. Relationship to clinical events. Ann N Y Acad Sci 1995;765:290-7.
7 Hillered L, Valtysson J, Endblad P, et al. Interstitial glycerol as a marker for membrane phospholipid degradation in the acutely injured human brain. $f$ Neurol Neurosurg Psychiatry 1998;64:486-91.

8 Hillered L, Persson L. Parabanic acid for monitoring of oxygen radical activity in the injured human brain. Neuroreport 1995;6:1816-20.

9 Lewen A, Hillered L. Involvement of reactive oxygen species in membrane phospholipid breakdown and energy perturbation after traumatic brain injury. F Neurotrauma 1998;15: 521-30.

10 Langemann $\mathrm{H}$, Feuerstein $\mathrm{T}$, Wolf $\mathrm{F}$, et al. Monitoring of uric acid in the human brain. In: 8th International Conference on In Vivo Methods. Stony Brook, New York: State University of New York, 1999:349-50.

11 Bächli H, Langemann H, Mendelowitsch A, et al. Microdialytic monitoring during cerebrovascular surgery. Neurol Res 1996;18:370-6.

12 Feuerstein T, Langemann H, Gratzl O, et al. A four lumen screwing device for multiparametric brain monitoring. Acta Neurochirurg (Wien) 2000;142:909-12.

13 Landolt H, Lutz TW, Langemann H, et al. Extracellular antioxidants and amino acids in the cortex of the rat: monitoring by microdialysis of early ischemic changes. 7 Cereb Blood Flow Metab 1992;12:96-102.

14 Hall ED. Cerebral ischaemia, free radicals and antioxidant protection. Biochem Soc Trans 1993;21:334-9.

15 Awasthi D, Church DF, Torbati D, et al. Oxidative stress following traumatic brain injury in rats. Surg Neurol 1997;47: 575-81.

16 Hall ED, Andrus PK, Yonkers PA. Brain hydroxyl radical generation in acute experimental head injury. $\mathcal{F}$ Neurochem 1993;60:588-94.

17 Marion DW, White MJ. Treatment of experimental brain injury with moderate hypothermia and 21 -aminosteroids. $\mathcal{f}$ Neurotrauma 1996;13:139-47.

18 Alessandri B, Basciani R, Langemann $\mathrm{H}$, et al. Chronic effects of an aminosteroid on microdialytically measured parameters after experimental middle cerebral artery occlusion in the rat. $\mathcal{F}$ Clin Neurosci 2000;7:47-51.

19 Kassell NF, Haley EC, Apperson-Hansen C, et al. Randomized, double-blind, vehicle-controlled trial of tirilazad mesylate in patients with aneurysmal subarachnoid hemorrhage: a cooperative study in Europe, Australia noid hemorrhage: a cooperative study in Europ

20 Lyrer P, Landolt H, Kabiersch A, et al. Levels of low molecular weight scavengers in the rat brain during focal molecular weight scavengers in the rat

21 Tayag EC, Nair SN, Wahhab S, et al. Cerebral uric acid increases following experimental traumatic brain injury in rat. Brain Res 1996;733:287-91.

22 O'Neill RD, Lowry JP. On the significance of brain extracellular uric acid detected with in-vivo monitoring techniques: a review. Behav Brain Res 1995;71:33-49.

23 Mendelowitsch A, Langemann $\mathrm{H}$, Alessandri B, et al. Microdialytic monitoring of the cortex during neurovascular surgery. Acta Neurochir Suppl (Wien) 1996;67:48-52.

24 Crespi F. Concomitant in vivo electrophysiological and voltammetric analysis indicate that ascorbic acid is a 1996;215:189-92.

25 Hillered L, Nilsson P, Ungerstedt U, et al. Trauma-induced increase of extracellular ascorbate in rat cerebral cortex. Neurosci Lett 1990;113:328-32.

26 Miele M, Fillenz M. In vivo determination of extracellular brain ascorbate. F Neurosci Methods 1996;70:15-19.

27 Landolt H, Langemann H, Gratzl O. On-line monitoring of cerebral pH by microdialysis. Neurosurgery 1993;32:10004.

28 Hutchinson PJ, O'Connell MT, Al-Rawi PG, et al. Clinical cerebral microdialysis: a methodological study. F Neurosurg 2000;93:37-43.

29 Lancelot E, Revaud ML, Boulu RG, et al. A microdialysis study investigating the mechanisms of hydroxyl radical formation in rat striatum exposed to glutamate. Brain Res mation in rat striat 